\title{
Article \\ Effect of Microstructure on Low-Temperature Fracture Toughness of a Submerged-Arc-Welded Low-Carbon and Low-Alloy Steel Plate
}

\author{
Byeong Chan Choi ${ }^{1,2}{ }^{\oplus}$, Byoungkoo Kim ${ }^{1}$, Byung Jun Kim ${ }^{1} \oplus$, Yong-Wook Choi ${ }^{1} \oplus$, Sang Joon Lee ${ }^{1}$, \\ Jong Bae Jeon ${ }^{3, *}$, Yangdo Kim ${ }^{2, *(D)}$ and Hyoung Chan Kim ${ }^{1, *}$ \\ 1 Dongnam Regional Division, Korea Institute of Industrial Technology, Busan 46938, Korea; \\ choibc@kitech.re.kr (B.C.C.); bungkim@kitech.re.kr (B.K.); jun7741@kitech.re.kr (B.J.K.); \\ yongwook@kitech.re.kr (Y.-W.C.); sjlee-ed@kitech.re.kr (S.J.L.) \\ 2 Department of Materials Science and Engineering, Pusan National University, Busan 46241, Korea \\ 3 Department of Materials Science and Engineering, Dong-A University, Busan 49315, Korea \\ * Correspondence: jbjeon@dau.ac.kr (J.B.J.); yangdo@pusan.ac.kr (Y.K.); chancpu@kitech.re.kr (H.C.K.); \\ Tel.: +82-51-200-7757 (J.B.J.); +82-51-510-3967 (Y.K.); +82-51-309-7414 (H.C.K.)
}

check for updates

Citation: Choi, B.C.; Kim, B.; Kim, B.J.; Choi, Y.-W.; Lee, S.J.; Jeon, J.B.; Kim, Y.; Kim, H.C. Effect of

Microstructure on Low-Temperature Fracture Toughness of a Submerged-Arc-Welded Low-Carbon and Low-Alloy Steel Plate. Metals 2021, 11, 1839. https://doi.org/ $10.3390 /$ met11111839

Academic Editor: Koh-ichi Sugimoto

Received: 19 October 2021

Accepted: 13 November 2021

Published: 16 November 2021

Publisher's Note: MDPI stays neutral with regard to jurisdictional claims in published maps and institutional affiliations.

Copyright: (c) 2021 by the authors. Licensee MDPI, Basel, Switzerland. This article is an open access article distributed under the terms and conditions of the Creative Commons Attribution (CC BY) license (https:/ / creativecommons.org/licenses/by/ $4.0 /)$.

\begin{abstract}
This study investigated the low-temperature fracture behavior of an 80-mm-thick lowcarbon steel plate welded by submerged arc. The relationship between impact absorbed energy and ductility-brittle transition temperature (DBTT) based on the microstructures was evaluated through quantitative analysis on grain size and complex constituent phases using advanced EBSD technique. The microstructure formed differently depending on the heat affections, which determined fracture properties in a low-temperature environment. Among the various microstructures of the heat-affected zone (HAZ), acicular ferrite has the greatest resistance to low-temperature impact due to its fine interlocking formation and its high-angle grain boundaries.
\end{abstract}

Keywords: thick plate steel; low-carbon steel; submerged-arc welding; welding microstructure; impact test

\section{Introduction}

Recently, the consumption of energy resources has been increasing with the continuing development of industry. The expansion of resource development systems such as oil pipelines and offshore plants for transporting resources is accelerating [1-9]. Since energy resources in areas close to land have almost been exhausted, it is necessary to explore and develop in extreme environments such as the polar regions and the deep sea. To be applied to environments with temperatures as low as $-40^{\circ} \mathrm{C}$, the mechanical properties of the materials constituting the structures must also be excellent in order to withstand such extreme environments. The combination of excellent mechanical properties and weldability in severe environments is thus essential for steels used for marine and ship structures $[1,6,8,10]$. In addition, most structures tend to be enlarged for efficiency and productivity, and thus thickening of the constituent steel is also necessary. Most structural steels require high strength and excellent toughness at the same time. When the steel is manufactured as a thick plate, an alloying element is added to obtain high strength, because the grain refinement effect by controlled rolling is insufficient $[1,5,11]$. However, through the optimization of chemical composition and the thermo-mechanical control process (TMCP), steel with bainite as the main microstructure can satisfy the combination of high strength and toughness $[1,3,9]$. Through accelerated cooling and controlled rolling, carbon equivalent can be reduced to a considerable extent, and excellent weldability can be secured [10]. However, in TMCP steel, each microstructure of the central and surface parts of a thick plate is formed differently, depending on the rolling reduction rate and the cooling 
rate according to the thickness [3]. This difference in microstructure causes differences in mechanical properties for each position of the plate, depending on the thickness.

Multi-layer welding is generally used for thick plate steels, including steels used in extreme environments, for industrial applications. Recently, as the size of steel structures has increased, high-heat-input welding has been used to improve productivity. Among the high-heat-input welding techniques, submerged arc welding (SAW) has demonstrated excellent production efficiency, but a large heat-affected zone (HAZ) is formed during the process. HAZ forms different structures between the base metal and the weld zone. The coarse grain heat-affected zone (CGHAZ) is the region with the worst mechanical properties $[2,4,7]$. Grain coarsening causes a fracture mechanism in which brittle cracks propagate due to external impact, having a direct effect on toughness degradation $[3,4]$. In the fine-grain heat-affected zone (FGHAZ), the mechanical properties deteriorate with lower uniformity of the microstructures [12]. Because various and complex microstructures affect mechanical properties such as strength and low-temperature toughness, it is very important to investigate the correlation between microstructure and mechanical properties [5].

As the plate thickness increases, the difference in microstructure and physical properties depending on the position through the thickness caused by TMCP and welding increases, which may cause catastrophic failure [3]. To minimize quality degradation in thick plates, it is important to identify low-temperature impact characteristics and fracture behavior depending on the microstructure of HAZ [6]. The main factors affecting the microstructure and mechanical properties of TMCP steels are various, and include the composition of the alloying elements, the rolling rate, and the cooling rate. The effects of major factors on microstructure and mechanical properties according to the welding method have been extensively studied [6]. However, in the case of 80-mm-thick TMCP steel, research on the microstructure of the rolling process and the microstructure of the heat-affected zone with respect to the welding process is still lacking. Therefore, this study analyzes the microstructure and low-temperature impact characteristics of a SAW-welded 80-mm TMCP steel, and investigated the correlation between them. In particular, this study focused on the quantitative analysis of microstructures. In particular, due to the complex microstructures of steels with complex thermal history, there is a limit to clearly distinguishing images on the basis of optical microscopy $(\mathrm{OM})$ and scanning electron microscopy (SEM) photography. Recently, quantitative analysis methods have been reported on the basis of various structures of low-carbon steel through electron back scatter diffraction (EBSD) analysis $[2-4,6,10]$, and this study quantitatively analyzes the microstructure of the HAZ of TMCP steel using the EBSD analysis method.

\section{Experimental Section}

\subsection{Material}

The chemical composition and manufacturing processes of the steel plates used in this study are shown in Table 1 and Figure 1 . Through the TMCP process, $80-\mathrm{mm}$-think steel plates were manufactured, with very low carbon content (about $0.14 \mathrm{wt} \%$ ). Various alloy components such as $\mathrm{Nb}, \mathrm{V}$, and Ti were added to improve the strength of the steel plates [1]. Figure 1 shows the transformation start temperature $\left(\mathrm{A}_{1}\right)$ and end temperature $\left(\mathrm{A}_{3}\right)$ from ferrite to austenite [13]. Before rolling, the slab was subjected to austenitizing heat treatment at $1070 \sim 1150{ }^{\circ} \mathrm{C}$ for $2 \mathrm{~h}$, and was rolled in air at a reduction ratio of $40 \sim 60 \%$ to produce an 80-mm plate. After the rolling process, it was water-cooled from $750{ }^{\circ} \mathrm{C}$ to $500{ }^{\circ} \mathrm{C}$ at a cooling rate of $4{ }^{\circ} \mathrm{C} / \mathrm{s}$ to $6^{\circ} \mathrm{C} / \mathrm{s}$, and then air-cooled to room temperature. The yield strength of the plate to be used as the base material for welding is $510 \mathrm{MPa}$, and the full dimensions were $500 \mathrm{~mm}(\mathrm{~W}) \times 1000 \mathrm{~mm}(\mathrm{~L}) \times 80 \mathrm{~mm}(\mathrm{H})$. 
Table 1. Chemical composition (wt\%) of the thick steel plate.

\begin{tabular}{|c|c|c|c|c|c|c|c|c|c|c|c|c|c|c|}
\hline Element & $\mathrm{C}$ & $\mathrm{Si}$ & Mn & $\mathbf{P}$ & $S$ & $\mathrm{Cr}$ & $\mathrm{Ni}$ & Mo & $\mathbf{N}$ & Al & $\mathrm{Cu}$ & $\mathrm{Nb}$ & $\mathrm{Ti}$ & $\mathrm{V}$ \\
\hline Content & 0.14 & 0.55 & 2.00 & 0.02 & 0.01 & 0.30 & 1.00 & 0.25 & 0.01 & 0.02 & 0.035 & 0.05 & 0.025 & 0.08 \\
\hline
\end{tabular}

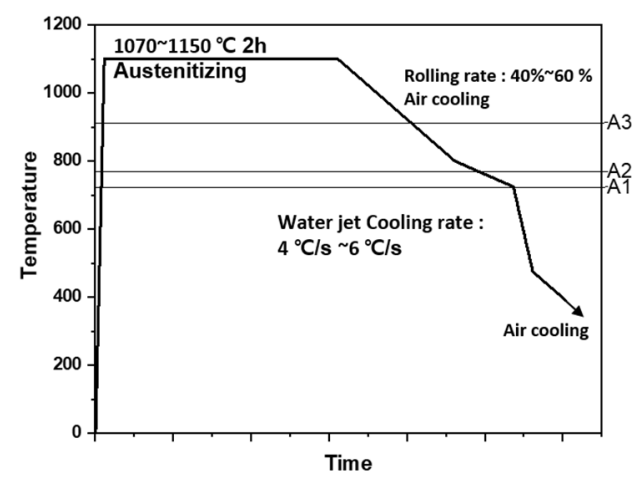

Figure 1. Schematic diagram of the manufacturing conditions of the present thick steel plate.

\subsection{Submerged Arc Welding ( $S A W$ )}

The welding wire used in the SAW process of the TMCP steel complied with the American Welding Association (AWS) standard. The base material was welded to a 80-mmthink TMCP steel plate with a K-groove. Figure 2 shows the schematic diagram of the shape of the K-groove. Seventeen multi-layer weldings were performed in each of the 1st and 2nd directions shown in Figure 2. And the specimens are summarized in Table 2. The chemical compositions of the welding wire and flux used for welding are shown in Table 3. Table 4 shows the welding current, voltage, welding speed, and preheating temperature for the welding process including heat input. The 12 locations of the specimen were chosen as shown in Figure 2 so that 4 locations were in the horizontal direction, i.e., base metal, $5 \mathrm{~mm}$, $2 \mathrm{~mm}, 0 \mathrm{~mm}$ from the fusion line (F.L.), while 3 locations were in the vertical direction, i.e., top, middle and bottom.
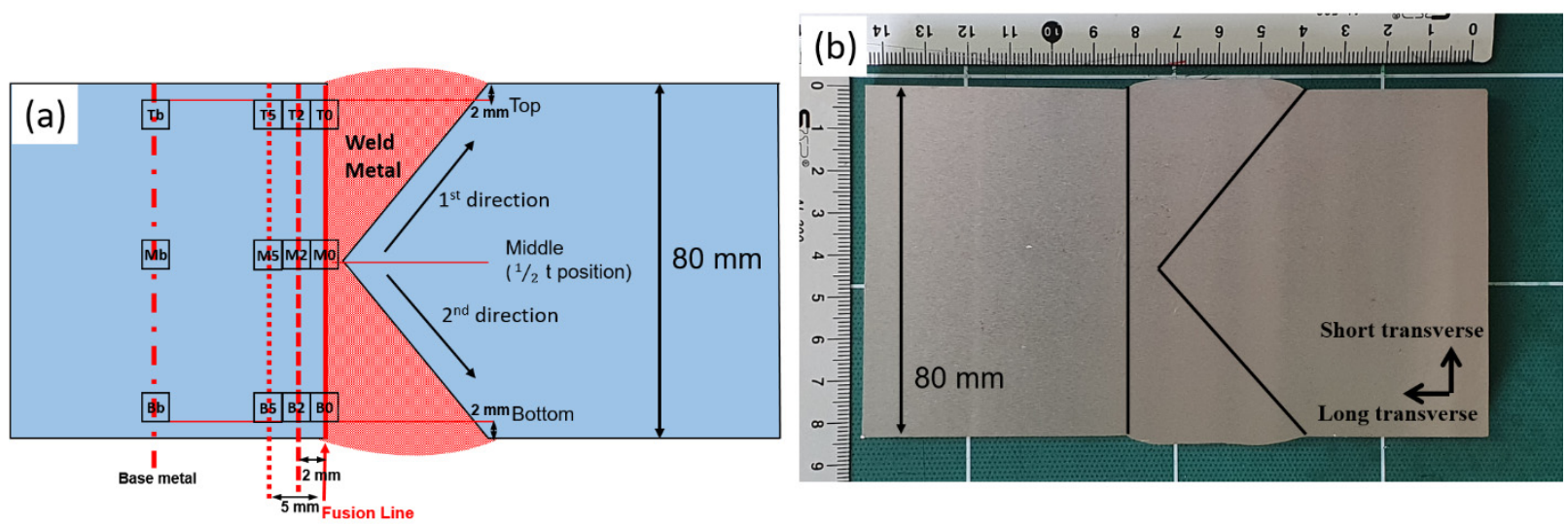

Figure 2. (a) Schematic illustration, (b) optical images of the welding joint and sampling positions of the specimens.

Table 2. Specimen information according to the twelve positions.

\begin{tabular}{cccccc}
\hline \multirow{2}{*}{ Specimen } & \multicolumn{4}{c}{ Horizontal Direction } \\
\cline { 3 - 6 } & & Base & $\mathbf{5} \mathbf{~} \mathbf{m}$ & $\mathbf{2} \mathbf{~ m m}$ & $\mathbf{0 ~} \mathbf{~ m m}$ \\
\hline \multirow{2}{*}{ Vertical } & Top & $\mathrm{Tb}$ & $\mathrm{T} 5$ & $\mathrm{~T} 2$ & $\mathrm{~T} 0$ \\
direction & Middle & $\mathrm{Mb}$ & $\mathrm{M} 5$ & $\mathrm{M} 2$ & $\mathrm{M} 0$ \\
& Bottom & $\mathrm{Bb}$ & $\mathrm{B} 5$ & $\mathrm{~B} 2$ & $\mathrm{~B} 0$ \\
\hline
\end{tabular}


Table 3. Chemical compositions ( $w \mathrm{t} \%$ ) of the flux and wire used in the welding process.

\begin{tabular}{|c|c|c|c|c|c|c|c|c|}
\hline Compositions & C & $\mathrm{Si}$ & Mn & $\mathbf{P}$ & $S$ & $\mathrm{Ni}$ & Mo & $\mathrm{Cu}$ \\
\hline Wire & $0.10 \sim 0.18$ & $\leq 0.30$ & $1.50 \sim 2.40$ & $\leq 0.025$ & $\leq 0.025$ & $0.7 \sim 2.75$ & $0.40 \sim 0.65$ & $\leq 0.35$ \\
\hline Compositions & \multicolumn{2}{|c|}{$\mathrm{SiO}_{2}+\mathrm{TiO}_{2}$} & \multicolumn{2}{|c|}{$\mathrm{CaO}+\mathrm{MgO}$} & \multicolumn{2}{|c|}{$\mathrm{Al}_{2} \mathrm{O}_{3}+\mathrm{MnO}$} & \multicolumn{2}{|c|}{$\mathrm{CaF}_{2}$} \\
\hline Flux & \multicolumn{2}{|c|}{20} & \multicolumn{2}{|c|}{40} & \multicolumn{2}{|c|}{20} & \multicolumn{2}{|c|}{15} \\
\hline
\end{tabular}

Table 4. Welding parameters.

\begin{tabular}{ccccccc}
\hline $\begin{array}{c}\text { Welding } \\
\text { Process }\end{array}$ & $\begin{array}{c}\text { Heat Input } \\
(\mathbf{k J} / \mathrm{cm})\end{array}$ & $\begin{array}{c}\text { Welding } \\
\text { Current (I, A) }\end{array}$ & $\begin{array}{c}\text { Welding } \\
\text { Voltage }(\mathbf{U}, \mathbf{A})\end{array}$ & $\begin{array}{c}\text { Welding Speed } \\
(\mathbf{c m} / \mathbf{m i n})\end{array}$ & $\begin{array}{c}\text { Preheating } \\
\text { Temperature } \\
\left({ }^{\circ} \mathbf{C}\right)\end{array}$ & $\begin{array}{c}\text { Inter-Pass } \\
\text { Temperature } \\
\left({ }^{\circ} \mathrm{C}\right)\end{array}$ \\
\hline SAW & $25 \sim 32$ & $600 \sim 610$ & $32 \sim 34$ & $40 \sim 45$ & $125 \sim 250$ & $125 \sim 250$ \\
\hline
\end{tabular}

\subsection{Microstructure}

To observe the microstructure, the long transverse-short transverse plane of each specimen was polished using \#600, \#1200, \#2000 SiC sand paper, and micro-polishing was carried out with $3-\mu \mathrm{m}$ and $1-\mu \mathrm{m}$ diamond paste. The etching solution was $5 \%$ Nital solution (ethanol $95 \mathrm{~mL}+$ nitric acid $5 \mathrm{~mL}$ ), and the microstructure was observed using an optical microscope (OM) and Field Emission Scanning Electron Microscopy (FE-SEM, MIRA3, TESCAN, Brno, Czech Republic). In addition, EBSD analysis was performed to observe the complex microstructure formed by controlled rolling and accelerated cooling and the HAZ in detail. For EBSD analysis, each specimen was finally polished with $0.25-\mu \mathrm{m}$ colloidal silica. EBSD analysis was performed using an FE-SEM (JEOL, 7200 F, Tokyo, Japan) and a detector (OXFORD, NanoAnalysis, High Wycombe, UK). Acceleration voltage and step size for the EBSD analysis were $20 \mathrm{kV}$ and $0.3 \mu \mathrm{m}$, respectively. Post-processing software (OIM, Tex SEM Laboratories, Inc., Provo, UT, USA) was used for crystallographic analysis and the resultant GOS (Grain Orientation Spread) map for quantitative analysis of the constituent phases and their fraction. In addition, average size and distribution of grains were analyzed using the post-processing software.

\subsection{Charpy Impact Testing}

Charpy V-notch impact tests were carried out with an instrumented Charpy automatic impact tester (Zwick/Roell, PSW750+TZE, Ulm, Germany) from $-140{ }^{\circ} \mathrm{C}$ to $20^{\circ} \mathrm{C}$ according to the ASTM E23 standard. For the impact test, V-notched specimens of $10 \times 10 \times 55 \mathrm{~mm}$ in size were taken from 12 different locations including the base metal and the heat-affected zone, as shown in Figure 2. The direction of the V-notch of the specimens was made in the rolling direction of the plate. The V-notch of each specimen was aligned with the exact location of interest, for example fusion line, $5 \mathrm{~mm}$ away from the fusion, etc. From the impact absorbed energy from CVN tests, the ductile-brittle transition temperature (DBTT) was calculated using the following hyperbolic tangent function [14,15]:

$$
\mathrm{E}=\mathrm{A}+\mathrm{B} \times \tanh \left[\mathrm{C}\left(\mathrm{T}-\mathrm{T}_{0}\right)\right]
$$

In the above equation, $\mathrm{E}$ is the Charpy absorbed energy, $\mathrm{A}, \mathrm{B}$, and $\mathrm{C}$ are constants, $\mathrm{T}$ is the test temperature, and $\mathrm{T}_{0}$ is the DBTT [16-18]. In addition, using the present instrumented Charpy impact tester, force-displacement curves were obtained to analyze crack initiation and propagation energy in detail. Using FE-SEM, fracture surfaces were observed to analyze the fracture mechanism. To observe crack propagation, the crosssection of the fractured surface was coated with nickel electroless plating at $90^{\circ} \mathrm{C}$ for $1 \mathrm{~h}$, then micro-polished in the same way as for microstructure observation. Finally, it was polished with colloidal silica, and EBSD analysis was performed in the same way as above. 


\section{Result and Discussion}

\subsection{Microstructure of the Base Metal, HAZ, and Weld}

TMCP steel generally shows various constituent phases, such as polygonal ferrite $(\mathrm{PF})$, granular bainite $(\mathrm{GB})$, acicular ferrite $(\mathrm{AF})$, bainitic ferrite $(\mathrm{BF})$, martensite/austenite constituent (MA), etc. In general, the above microstructure can be morphologically classified as follows $[9,19]$. PF takes the shape of a polygon and is formed in the temperature range of binary phase between austenite and ferrite at a low cooling rate [1,11]. GB has an island-shaped secondary phase inside the grains and is formed with the slowest cooling rate among bainitic microstructures, whereas $\mathrm{AF}$ is formed through faster cooling rate than GB and is known to show excellent strength and toughness due to its fine and irregular crystal orientation $[7,20]$. BF is formed at a relatively low temperature and a fast cooling rate, and its interior is composed of parallel acicular ferrites. The fraction of each phase varies depending on the alloy composition and TMCP conditions $[1,3,10]$.

Figures 3 and 4 show microstructures observed by OM and SEM of the base material and HAZ. Figure $3 a, e, i$ and Figure $4 a, e, i$ show the microstructures of the top, middle and bottom of the base metal plate. It was observed that the base metal consisted of a mixture of $\mathrm{PF}, \mathrm{GB}$ and $\mathrm{AF}$. In the case of $\mathrm{Mb}$, referring to the middle of the base metal $(\mathrm{Mb})$, coarse microstructures of PF and GB were mostly observed, while fine microstructures of AF were considerably observed in the $\mathrm{Tb}$ and $\mathrm{Bb}$. This microstructural dependency on the location of the present steel plate can be explained by the difference in cooling rate and magnitude of plastic strain. That is, the finer microstructure observed in $\mathrm{Tb}$ and $\mathrm{Bb}$ is thought to be due to the higher cooling rate and the higher rolling reduction rate in the surface of the plate, compared to the $\mathrm{Mb}[1,4,6,8]$.
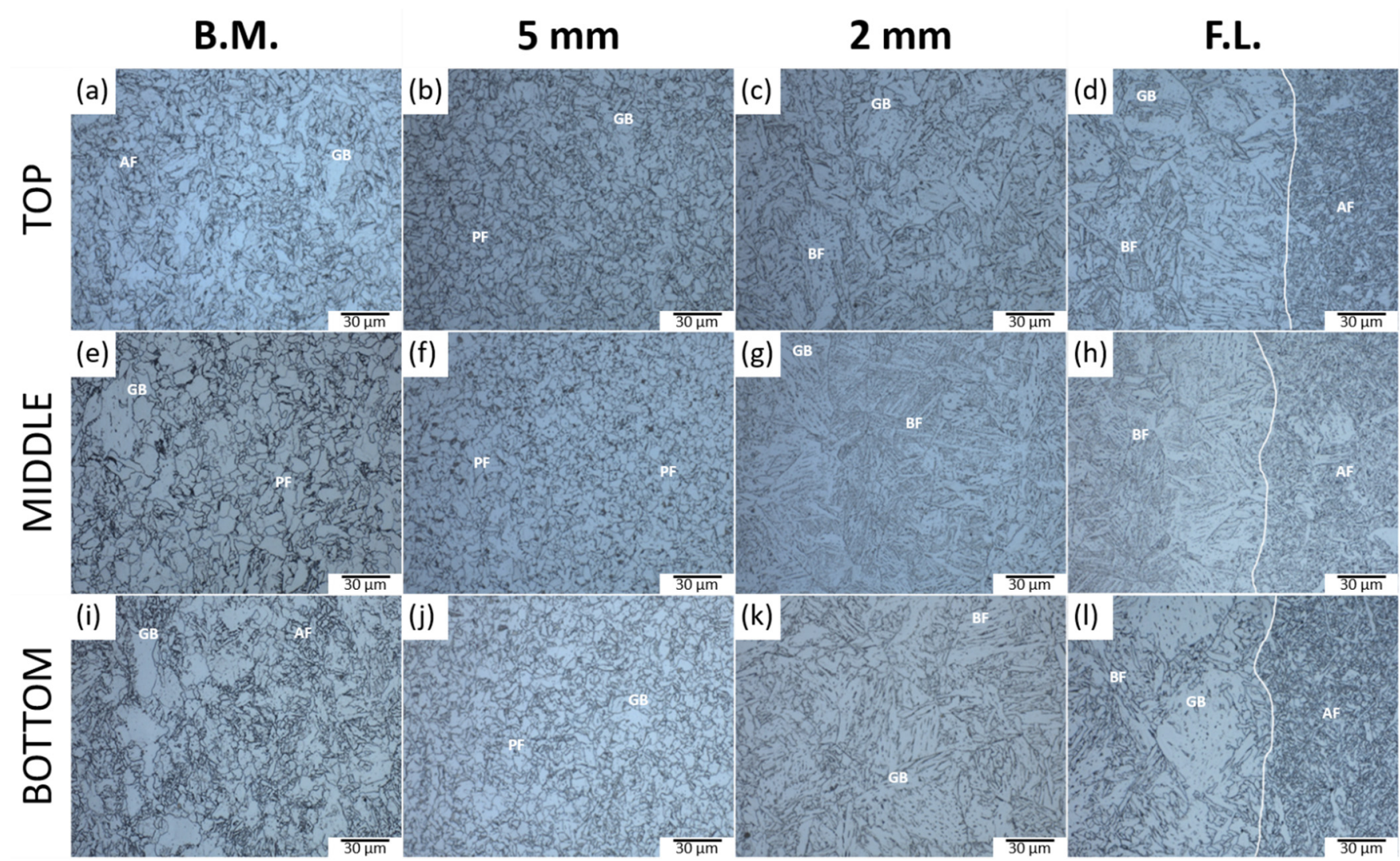

Figure 3. Optical micrographs of the base metal and HAZ: (a) base metal, (b) $5 \mathrm{~mm}$ from F.L., (c) $2 \mathrm{~mm}$ from F.L., (d) F.L. of top; (e) base metal, (f) $5 \mathrm{~mm}$ from F.L., (g) $2 \mathrm{~mm}$ from F.L., (h) F.L. of middle; (i) base metal, (j) $5 \mathrm{~mm}$ from F.L., (k) $2 \mathrm{~mm}$ from F.L., (1) F.L. of bottom. 


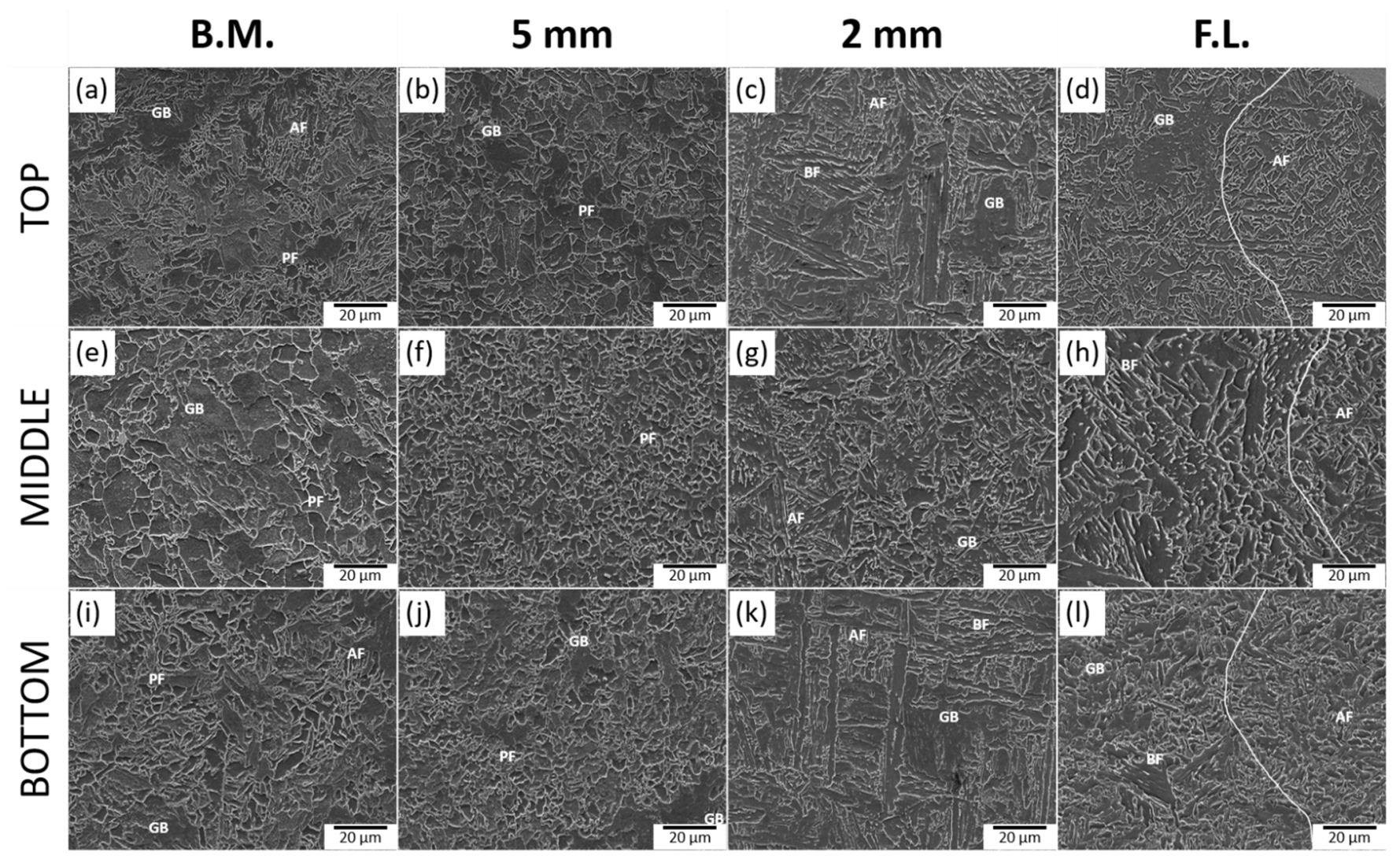

Figure 4. Microstructures of the base metal and HAZ using scanning electron microscopy (SEM): (a) base metal, (b) $5 \mathrm{~mm}$ from F.L., (c) $2 \mathrm{~mm}$ from F.L., (d) F.L. of top; (e) base metal, (f) $5 \mathrm{~mm}$ from F.L., (g) $2 \mathrm{~mm}$ from F.L., (h) F.L. of middle; (i) base metal, (j) $5 \mathrm{~mm}$ from F.L., (k) $2 \mathrm{~mm}$ from F.L., (1) F.L. of bottom.

Coarse mixed microstructures of BF and GB were observed along the AF boundary in T0, M0, and B0, which are the SAW fusion line (Figure 3d,h,l and Figure 4d,h,l). In $\mathrm{T} 2$ and $\mathrm{B} 2$, coarse GB, BF, and AF were observed, whereas in M2, densely formed AF along with GB and BF was mainly observed. PF was mainly formed and GB was also observed in T5 and B5 (Figure 3b,j and Figure 4b,j), and fine PF was mainly observed in M5 (Figures $3 \mathrm{f}$ and $4 \mathrm{f}$ ). According to the OM and SEM micrographs, it was observed that the fraction of GB and BF decreased and the fraction of PF increased away from the weld line. Similar microstructures were observed in the specimens closer to the surface such as $\mathrm{T} 5, \mathrm{~B} 5, \mathrm{~T} 2$, and $\mathrm{B} 2$.

It is well established that the cooling rate of the steel plate varies depending on the welding sequence of multi-pass welding and consequently affects the microstructure evolution [10]. In our case, welding heat was accumulated during the present multi-pass welding so that the cooling rate in the center became higher than that at the surface. Accordingly, the microstructure of the center (Figure 3f,g) was densely formed, while the microstructure of surface became coarser than the center, since the accumulated heat by multi-pass welding possibly slowed down the cooling rate.

In the case of complex bainitic microstructures of the present TMCP steel, it is very difficult to distinguish grain boundary clearly only by the surface morphology. In this study, in order to more objectively distinguish microstructure types and grain boundary, grain boundary mapping was conducted using EBSD. Figure 5 shows grain boundary maps of the base metal, the HAZ, and the fusion line. In Figure 5, a low-angle grain boundary (LAGB) with misorientation angles $2^{\circ}<\theta<15^{\circ}$ and high-angle grain boundary (HAGB) with angles $>15^{\circ}$ are drawn in green and black, respectively. In this study, the average grain size was also measured based on the HAGB, and is listed in Table 5. 


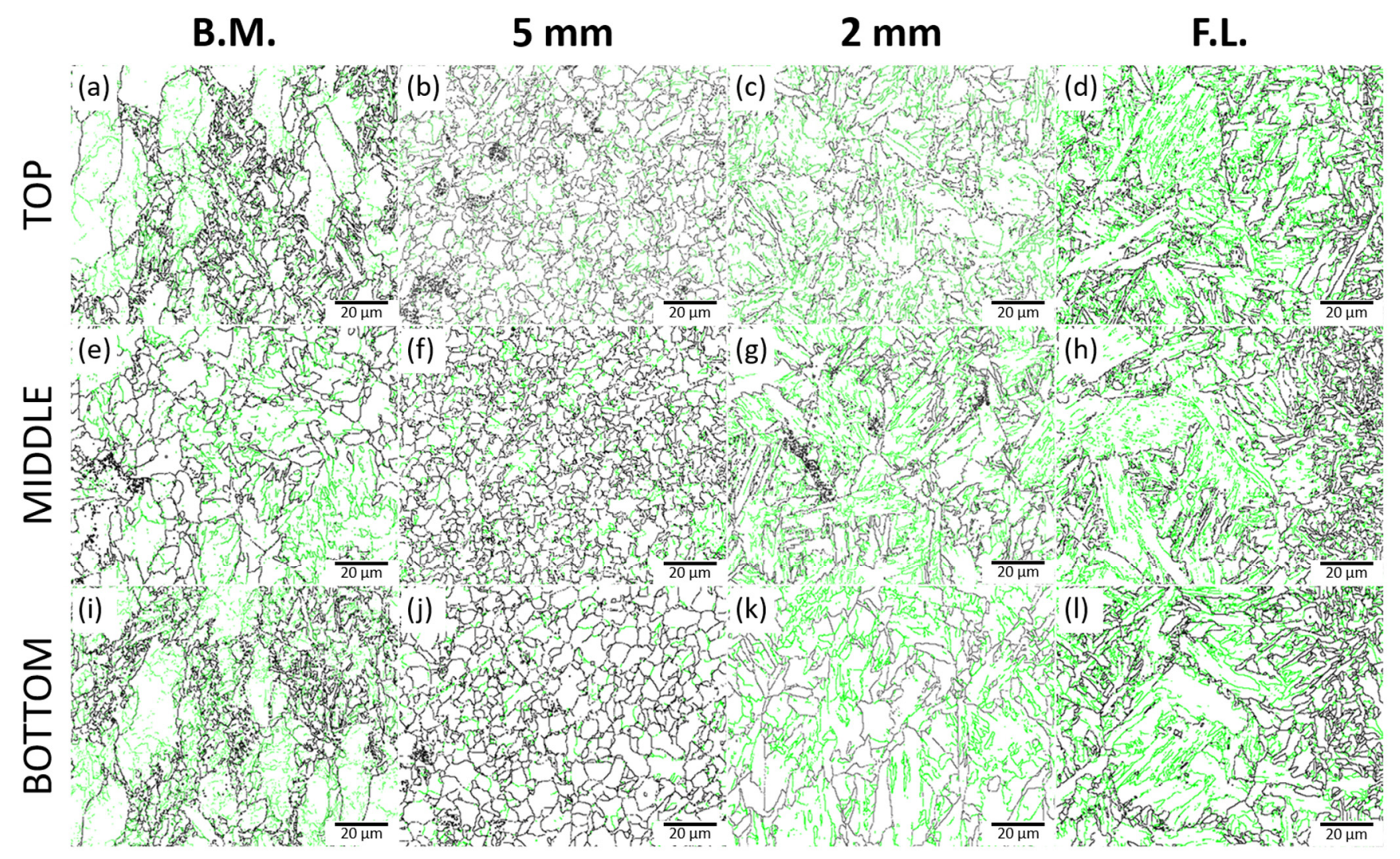

Figure 5. Grain boundary (GB) map of the base metal and HAZ: (a) base metal, (b) $5 \mathrm{~mm}$ from F.L., (c) 2 mm from F.L., (d) F.L. of top; (e) base metal, (f) $5 \mathrm{~mm}$ from F.L., (g) $2 \mathrm{~mm}$ from F.L., (h) F.L. of middle; (i) base metal, (j) $5 \mathrm{~mm}$ from F.L., (k) $2 \mathrm{~mm}$ from F.L., (1) F.L. of bottom.

Table 5. Microstructure area fraction (\%) and average grain size of base metal and HAZ.

\begin{tabular}{cccccc}
\hline \multirow{2}{*}{ Specimen } & \multicolumn{4}{c}{ Microstructure Area Fraction (\%) } & \multirow{2}{*}{ Average Grain Size $(\mu \mathbf{m})$} \\
\cline { 2 - 5 } & PF & GB & AF & BF & \\
\hline Tb & 11.8 & 54.0 & 34.2 & - & $12.5 \pm 10.3$ \\
T5 & 70.0 & 15.7 & 14.3 & - & $5.2 \pm 2.4$ \\
T2 & 8.6 & 32.8 & 10.9 & 47.7 & $12.2 \pm 6.7$ \\
T0 & 4.5 & 22.1 & 32.8 & 40.7 & $13.5 \pm 11.8$ \\
\hline Mb & 27.6 & 59.5 & 12.8 & - & $15.5 \pm 12.6$ \\
M5 & 59.3 & 7.0 & 33.7 & - & $4.7 \pm 2.3$ \\
M2 & 7.4 & 20.0 & 6.8 & 65.8 & $12.5 \pm 7.9$ \\
M0 & 4.5 & 20.5 & 40.0 & 35.0 & $20.7 \pm 19.4$ \\
\hline Bb & 16.0 & 52.8 & 31.3 & - & $11.8 \pm 9.2$ \\
B5 & 69.9 & 16.6 & 13.5 & - & $5.7 \pm 2.5$ \\
B2 & 8.8 & 37.1 & 12.4 & 41.7 & $16.9 \pm 10.2$ \\
B0 & 6.0 & 33.7 & 24.1 & 36.2 & $17.8 \pm 17.3$ \\
\hline
\end{tabular}

The grain sizes of $\mathrm{Tb}$ and $\mathrm{Bb}$ were measured as $12.5 \pm 10.3 \mu \mathrm{m}$ and $11.8 \pm 9.2 \mu \mathrm{m}$, respectively, while that of $\mathrm{Mb}$ was measured as $15.5 \pm 12.6 \mu \mathrm{m}$. This grain size distribution was due to the TMCP process by which fine crystal grains were formed at the surface ( $\mathrm{Tb}$, $\mathrm{Bb}$ ) due to a large reduction rate and a fast cooling rate, while coarse grains were formed in the central part due to a slow cooling rate. On the other hand, the grain size became smaller as the distance from the fusion line increased. For example, the grain sizes of T0, T2 and T5 were measured as $13.5 \pm 11.8 \mu \mathrm{m}, 12.2 \pm 6.7 \mu \mathrm{m}$, and $5.2 \pm 2.4 \mu \mathrm{m}$, respectively. B0, B2 and B5 were measured to be $17.8 \pm 17.3 \mu \mathrm{m}, 16.9 \pm 10.2 \mu \mathrm{m}$, and $5.7 \pm 2.5 \mu \mathrm{m}$, 
respectively. M0, M2 and M5 were measured to be $20.7 \pm 19.4 \mu \mathrm{m}, 12.5 \pm 7.9 \mu \mathrm{m}$, and $4.7 \pm 2.3 \mu \mathrm{m}$. From the grain size mapping results, it is noteworthy that $\mathrm{M} 0$ specimens had clear bi-modal grain size distribution bordering on the fusion line. Additionally, M5 has smaller grains than T5 and B5 because the central part experienced a faster cooling rate than the surface $[10,21]$.

Quantitative phase volume analysis was performed by applying grain orientation spread (GOS) mapping [22-24]. GOS mapping is a method of quantitatively measuring the microstructure of each grain by calculating the average misorientation between each point in the grain. GOS analysis classifies the microstructure by matching the structure shape, grain orientation, and LAGB within the grains $[25,26]$. The PF was classified into a structure with a misorientation value of about $2-3^{\circ}$ or less, a low dislocation density inside the grain, and did not have any secondary phase $[6,10]$. GB and BF have a misorientation difference of $3^{\circ}$ or more $[26,27]$. The GB and BF were classified into higher misorientation values (approximately $3-5^{\circ}$ or less) than PF and have coarse grains. GB has relatively low internal dislocation density, and the irregular dislocation shape, while BF has relatively high dislocation density and dislocation shape is classified as lath type. In the case of AF, after identifying $\mathrm{PF}, \mathrm{GB}$, and $\mathrm{BF}$, the remaining was classified as $\mathrm{AF}$, in which the areas had fine grains with a higher dislocation density than PF. Figure 6 is the result of the GOS analysis of each microstructure [28-30], and Table 5 shows the fraction of the microstructure in each area.

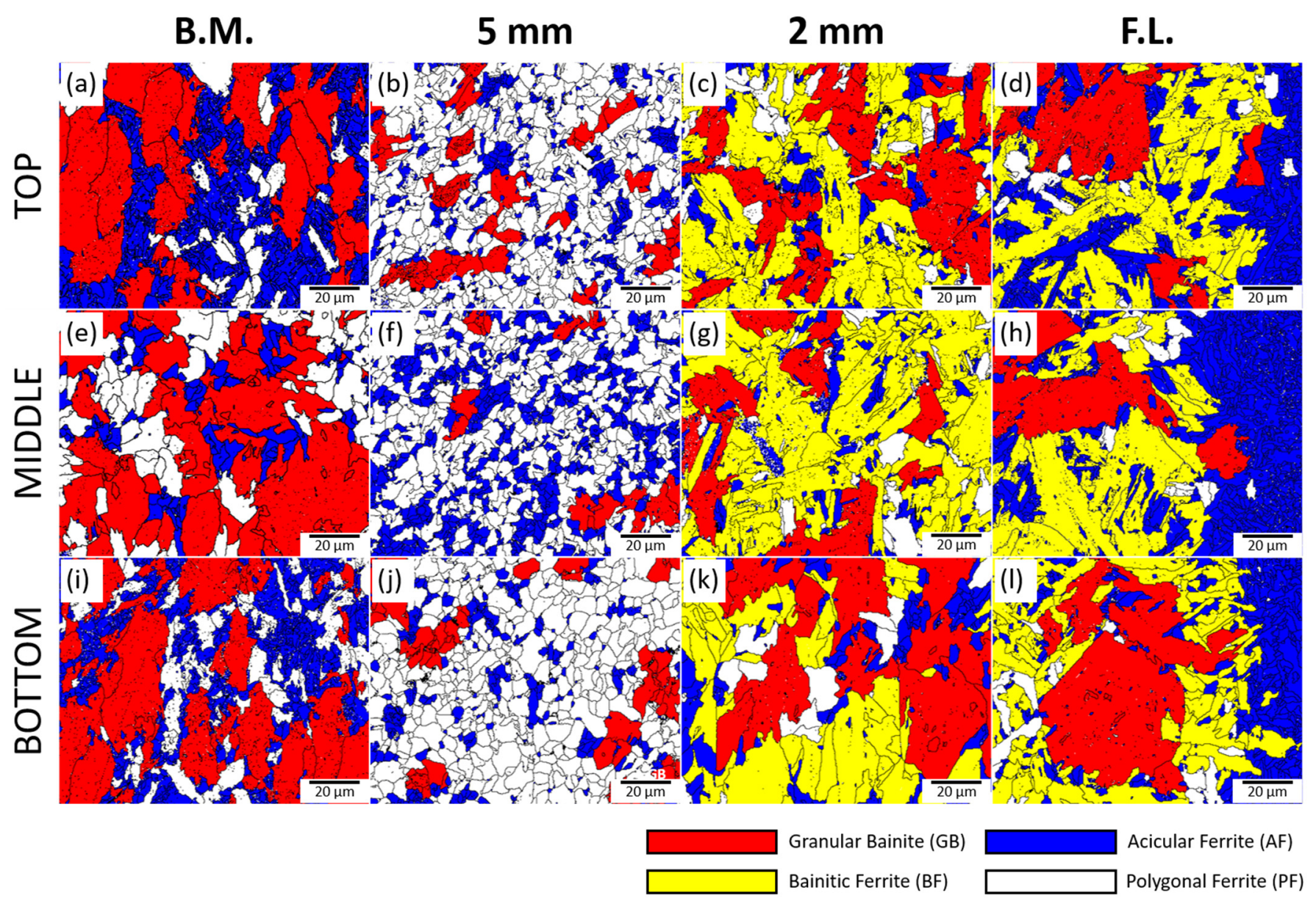

Figure 6. Phase analysis of base metal and HAZ according to grain orientation spread (GOS): (a) base metal, (b) $5 \mathrm{~mm}$ from F.L., (c) $2 \mathrm{~mm}$ from F.L., (d) F.L. of top; (e) base metal, (f) $5 \mathrm{~mm}$ from F.L., (g) $2 \mathrm{~mm}$ from F.L., (h) F.L. of middle; (i) base metal, (j) $5 \mathrm{~mm}$ from F.L., (k) $2 \mathrm{~mm}$ from F.L., (l) F.L. of bottom. 
The microstructure fraction of the base metal was symmetrical with the rolling process. GB showed a similar fraction, while PF increased, and AF decreased compared to the surface part. It can be seen that in $\mathrm{Mb}$, the fraction of PF increased due to the slow cooling rate compared to the surface, and the fraction of AF formed at the fast cooling rate decreased. In the process of controlled rolling, the large grains were formed in the central region $(\mathrm{Mb})$ under the influence of a low rolling force. In the fusion line, the heat effect caused recrystallization, and microstructure was formed completely different from the base metal. It can be seen that the fraction of AF and BF is high due to direct welding heat at the welding line and rapid cooling. Also, all weld joints along the fusion line were formed with AF. Due to the direct heat input of welding, the difference in the fraction of AF and BF along the vertical direction is not large. Compared with the base metal, PF and GB were transformed mostly into most of BF and AF. Compared to T2 and B2, M2 shows a decrease in the GB fraction and a large increase in the BF fraction. The increase in BF, which has a relatively fast cooling rate, is caused by the fact that the $\mathrm{M} 2$ region cooled rapidly. It can be seen that T2 and B2, which have relatively many GB, cooled more slowly than M2. Even though it is close to the fusion line, a difference in cooling rate occurs between the surface and the center. In M5, there was more AF compared to T5 and B5. This is because M5 cooled faster than the surface part, increasing the AF fraction, and BF did not appear due to the lower heat input amount compared to CGHAZ. Comparing the 2-mm area with the 5-mm area, there are many AF and BF that have relatively faster cooling in the middle compared to the top and bottom. It can be seen that in the HAZ, the middle area cooled faster than the top and bottom. M2 and M5 also appear to have the smallest particle size previously measured. Considering this, BF, AF, and GB mainly appear in the region close to the weld line through recrystallization and grain growth, and PF mainly appears in areas $5 \mathrm{~mm}$ away from the welding line due to recrystallization.

\subsection{Impact Toughness of TMCP Steel and SAW Heat-Affected Zone}

Figure 7 shows the results of the Charpy impact tests conducted from $-140{ }^{\circ} \mathrm{C}$ to room temperature. As the temperature of the impact tests decreased, the absorbed energy rapidly decreased. This is a typical ductile-brittle behavior of steels with a BCC crystal structure $[8,10,31]$. It is well known that the upper shelf energy (USE) is affected by the type of microstructure, volume fraction, and grain size, whereas the DBTT is mainly affected by the grain size of the microstructure [32-34]. The USE and DBTT of base metals were as high as about $280 \mathrm{~J}$ and $-70{ }^{\circ} \mathrm{C}$, while those of fusion lines were about $250 \mathrm{~J}$ and $-50{ }^{\circ} \mathrm{C}$. This higher USE and lower DBTT shown in the base compared to the fusion line were attributed to by higher volume fraction of GB and AF [34].

The absorbed energy of the base material was affected by the TMCP process. Compared to the surface part, the lower the impact energy and the higher the DBTT, the less it was affected by rolling and cooling. In the case of $\mathrm{Mb}$, it can be seen that the DBTT is rather high due to the decrease in the AF fraction. USE can be increased by microstructures that can affect energy absorption during ductile fracture. The GB with a relatively high density of dislocations inside the grains improves USE [34]. The USE of the base metal at $280 \mathrm{~J}$ is caused by a high fraction of GB, and the DBTT at $-70{ }^{\circ} \mathrm{C}$ is due to the excellent toughness of the AF structure.

Under the influence of welding heat, the fusion line exhibited the worst lowtemperature toughness. The USE of T0, M0, and B0, which are SAW fusion line specimens, were $260 \mathrm{~J}, 265 \mathrm{~J}$, and $255 \mathrm{~J}$, respectively, and the DBTT was $-50{ }^{\circ} \mathrm{C},-45^{\circ} \mathrm{C}$, and $-50{ }^{\circ} \mathrm{C}$.

DBTT increased and USE decreased as the distance from the fusion line increased. In the case of the center, the fraction and grain size of the microstructure changed as it moved away from the weld line, but there was no significant change in USE and DBTT. Lowtemperature toughness was not only affected by the horizontal distance from the weld line, but also by the vertical position. At $2 \mathrm{~mm}$ from the welded zone, the USE decreased toward the center and the DBTT increased. M2 showed lower toughness in the entire temperature 
range compared to the surface part. This is because the fraction of BF microstructure, which has higher strength, but low toughness compared to AF, was larger [5]. At low temperature, the BF structure exhibits different characteristics from the finely dispersed AF structure with HAGB [27]. During low-temperature impact tests, the stress concentration around a hard microstructure, such as BF, acts as a major factor in crack formation [2,5,7]. It can be seen that not only the fraction of $\mathrm{BF}$, but also the fraction of AF is lower than that of $\mathrm{T} 2$ and $\mathrm{B} 2$. AF is a microstructure that improves crack propagation resistance because it has HAGB. It can be seen that T2 and B2 have higher crack propagation resistance due to the presence of the AF structure, and the DBTT of M2 is higher than that of M2. In addition, the USE of T2 and B2, which has a higher GB fraction than M2, is about $30 \mathrm{~J}$ higher.
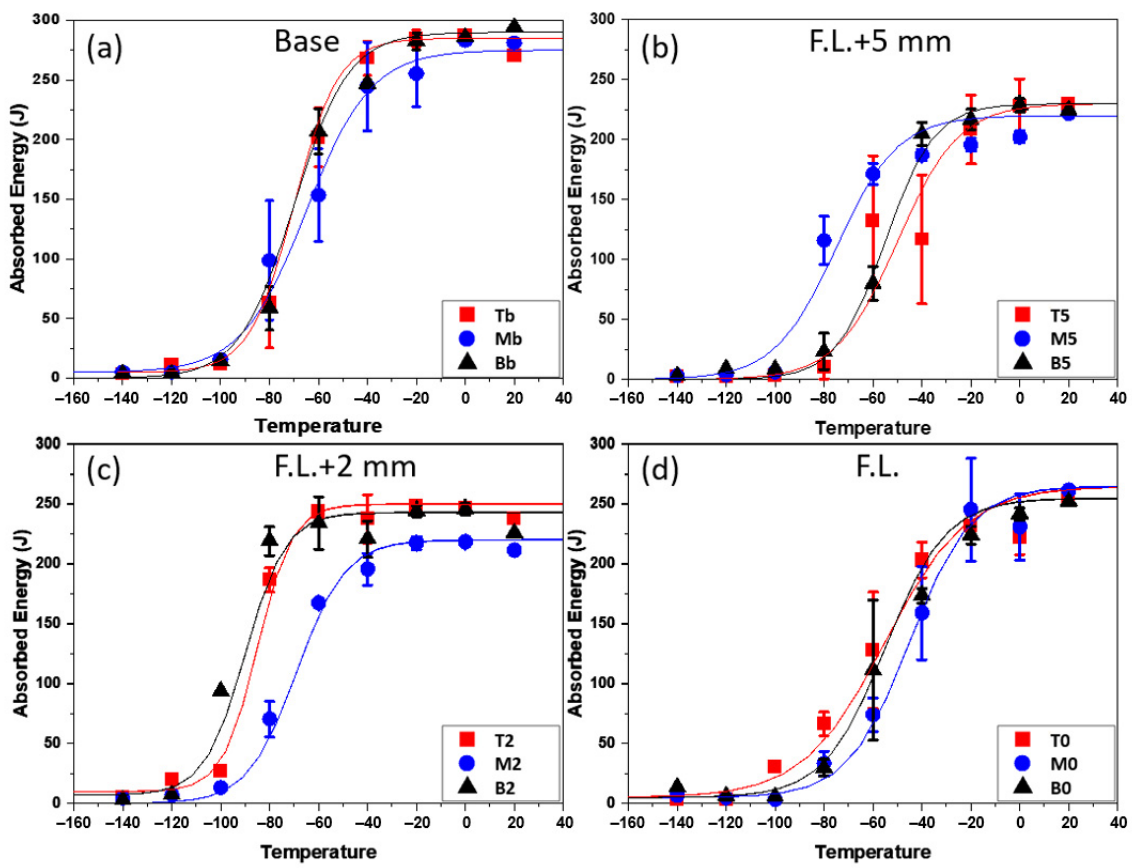

Figure 7. Charpy impact energy of the TMCP Base metal and heat-affected zone: (a) base metal, (b) fusion line $+5 \mathrm{~mm}$, (c) fusion line $+2 \mathrm{~mm}$ (d) fusion line.

At a distance of $5 \mathrm{~mm}$ from the fusion line, both USE and DBTT decreased in the center compared to the surface. It can be seen that the DBTT of T5 and B5 is the worst for the HAZ. Other specimens consist of a matrix of bainite such as GB and BF, but T5, M5, and B5 have a matrix of PF. The PF-based steel has a higher DBTT than the bainite-based steel [12]. Among the above specimens, the DBTT of M5 is the lowest, which has a low PF fraction and a high AF fraction. In addition, it can be observed that the DBTT is lower, because M5, which has a small effective grain size, has relatively high crack resistance during low-temperature brittle fracture [10]. T5 and B5 have about 10\% more GB fraction and $10 \mathrm{~J}$ higher USE compared to M5.

Table 6 summarizes the values of USE and DBTT. It can be seen that the DBTT of the M2 specimen located at a distance of $2 \mathrm{~mm}$ from the welding line is higher than that of T2 and B2, and the USE is also lower. Additionally, unlike T5 and B5, the USE of M5 is low, but it can be seen that DBTT is the best result. These results indicate that the microstructure transformation under the influence of welding heat affects the transition of initiation and propagation energy, respectively, and it can be speculated that there is a correlation between the microstructure fraction and grain size. 
Table 6. USE and DBTT of base metal and HAZ.

\begin{tabular}{ccccccccc}
\hline \multirow{2}{*}{ Position } & \multicolumn{2}{c}{ Base Metal } & \multicolumn{2}{c}{ F.L.+ $\mathbf{5} \mathbf{~ m m}$} & \multicolumn{2}{c}{ F.L.+ $\mathbf{2}$ mm } & \multicolumn{2}{c}{ F.L. } \\
\cline { 2 - 8 } & USE (J) & DBTT $\left({ }^{\circ} \mathbf{C}\right)$ & USE (J) & DBTT $\left({ }^{\circ} \mathbf{C}\right)$ & USE $(J)$ & DBTT $\left({ }^{\circ} \mathbf{C}\right)$ & USE $(J)$ & DBTT $\left({ }^{\circ} \mathbf{C}\right)$ \\
\hline Top & 285 & -70 & 230 & -50 & 250 & -85 & 260 & -50 \\
Middle & 280 & -65 & 220 & -75 & 220 & -70 & 265 & -45 \\
Bottom & 290 & -70 & 230 & -55 & 245 & -90 & 255 & -50 \\
\hline
\end{tabular}

\subsection{Correlation between Microstructure and Charpy Absorbed Energy}

Figure 8 shows the force-displacement curves of the HAZs obtained at $-60{ }^{\circ} \mathrm{C}$. The total absorbed energy can be described as the sum of the crack initiation energy $\left(E_{\mathrm{i}}\right)$ and the crack propagation energy $\left(E_{p}\right)$ [35-38]. There are several methods for analyzing instrumented data, and there are studies that it is reasonable to classify based on the midpoint between force at general yield and maximum force [39,40]. In Figure 8a-c, the Charpy absorbed energies at $-60{ }^{\circ} \mathrm{C}$ of T5, M5, and B5 were $56.4 \mathrm{~J}, 159.7 \mathrm{~J}$, and $65.0 \mathrm{~J}$, respectively. Ei and Ep of T5 were $24.99 \mathrm{~J}, 31.40 \mathrm{~J}$, and those of B5 were $19.03 \mathrm{~J}$, and $45.96 \mathrm{~J}$, respectively, showing relatively low absorbed energies during crack initiation and propagation. However, M5 had $78.73 \mathrm{~J}$ for crack initiation and $80.96 \mathrm{~J}$ for crack propagation, showing higher absorbed energies compared to T5 and B5. It is believed that these higher absorbed energies for M5 are due to the higher fraction of AF [6], smaller grain sizes and higher fraction of HAGB [1].
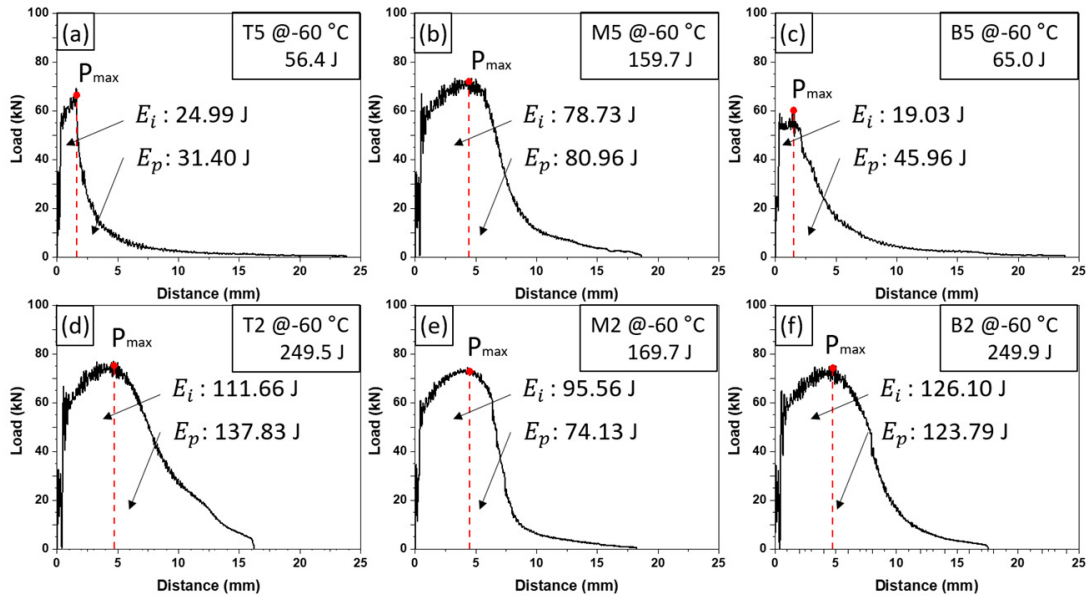

Figure 8. Force $(\mathrm{kN})$-displacement $(\mathrm{mm})$ curves obtained for instrumented Charpy impact tests at $-60{ }^{\circ} \mathrm{C}$ : (a) $5 \mathrm{~mm}$ from F.L. of top, (b) $5 \mathrm{~mm}$ from F.L. of middle, (c) $5 \mathrm{~mm}$ from F.L. of bottom; (d) $2 \mathrm{~mm}$ from F.L. of top, (e) $2 \mathrm{~mm}$ from F.L. of middle, (f) $2 \mathrm{~mm}$ from F.L. of bottom.

Conversely, absorbed energies of the specimens $2 \mathrm{~mm}$ away from the fusion line showed different trends. It is known that low-temperature toughness is excellent when $\mathrm{AF}$ and PF are uniformly mixed as secondary phases on a bainite matrix such as GB and $\mathrm{BF}[10,12,25,41,42]$. Here, the central specimen, M2, showed lower absorbed energy than the surface specimens, T2 and B2. This is caused by a large fraction of the BF observed in M2, which is known to have poor toughness at low temperatures, since trans-granular fracture occurs across grains upon impact at low temperature due to the presence of highdensity dislocations inside the BF structure [27]. In addition, it can be seen that the uniform dispersion of the secondary phases (such as $\mathrm{AF}, \mathrm{PF}$ ) was not achieved due to a large fraction of BF. Therefore, it can be observed that M2 exhibited brittle behavior at $-60^{\circ} \mathrm{C}$.

Figure 9 shows low-scale optical micrographs of cross-sectional areas of Charpy impact test specimens fractured at $-60^{\circ} \mathrm{C}$. T5 showed a completely fractured surface and a linear and relatively straight crack propagation path, as indicated by the red line in Figure 9a. On the other hand, M5 showed a fracture surface with a non-fractured area, or deformed 
area, marked by a yellow line, and the crack propagation path was relatively shorter and more irregular than T5. Non-fractured areas and frequent deviations of crack paths are usually found in specimens having high crack propagation energy and thus M5 showed higher CVN energy than T5. In this regard, T2 showed the highest CVN energy among those in Figure 9, because of having the shortest fracture length of $3.8 \mathrm{~mm}$ and shorter crack propagation length, as indicated in Figure 9b.

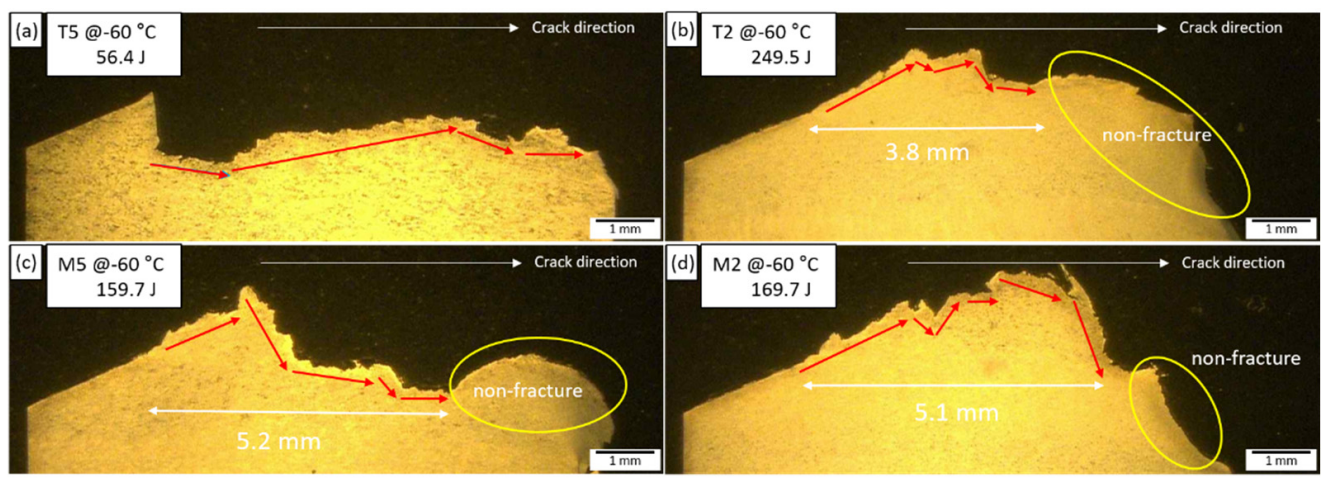

Figure 9. Optical micrographs of the cross-sectional areas of fracture surfaces of the Charpy impact test specimens fractured at $-60^{\circ} \mathrm{C}$ : (a) $5 \mathrm{~mm}$ from F.L., (b) $2 \mathrm{~mm}$ from F.L. of top; (c) $5 \mathrm{~mm}$ from F.L., (d) $2 \mathrm{~mm}$ from F.L. of middle.

Figure 10 shows the crack propagation path of the fractured specimen according to the microstructure. Figure $9 \mathrm{~b}$ is the cross-sectional areas of fracture surface of M5 with the highest AF fraction. Some researchers defined the grain boundary of AF as a highangle grain boundary and said that it showed excellent low-temperature properties $[43,44]$. Therefore, M5 can maintain absorbed energy even at low temperature. As shown in Figure 9a, T5 showed a straight crack propagation path through a bundle of AF. In the papers studied previously, when discussing AF crack resistance, there is a report that crack resistance is not high when crossing through the AF packet which binds AFs of similar crystallographic orientation [45]. This is because the crystal orientation within the packet is similar, so deviations in crack path may not be noticeable. Accordingly, the straight crack path as shown in Figure 9a could be regarded as the result of crack propagating through AF packet.

On the other hand, T2 showed high absorbed energy. The reason it has high absorbed energy is as follows, even though the AF fraction is low. According to previous researchers, when AF is dispersed in a secondary phase on a bainite matrix, low-temperature toughness is excellent, and properly dispersed AF can have high crack propagation resistance [10,25,41,42]. Looking at the crack path of T2, severe deviation of the crack is observed, and it can be checked that deflection occurs in AF between GB and BF. Therefore, as in previous studies, it is considered to have high absorbed energy even at low temperatures. M2 and B2 also showed high absorbed energy due to AF dispersion in the bainite base, but M2 did not properly disperse due to the increase in BF and decrease in AF. That is, it appeared that the absorbed energy of M2 decreased. In addition, the effect of dispersion of AF on banite matrix such as BF and GB is superior to that when AF is dispersed on the PF matrix at low temperature [12]. Therefore, better absorbed energy was shown in T2 and M2 in which bainite was formed than in T5 and M5 in which PF was the matrix. In conclusion, in the case of T5, which shows low absorbed energy even with high AF fraction in this composition, it is considered that AF did not effectively resist crack propagation by forming packets. On the other hand, in the case of T2, even though the fraction of AF is low, it shows high absorbed energy, because it effectively resists crack propagation by dispersion of AF into the fine secondary phase. 


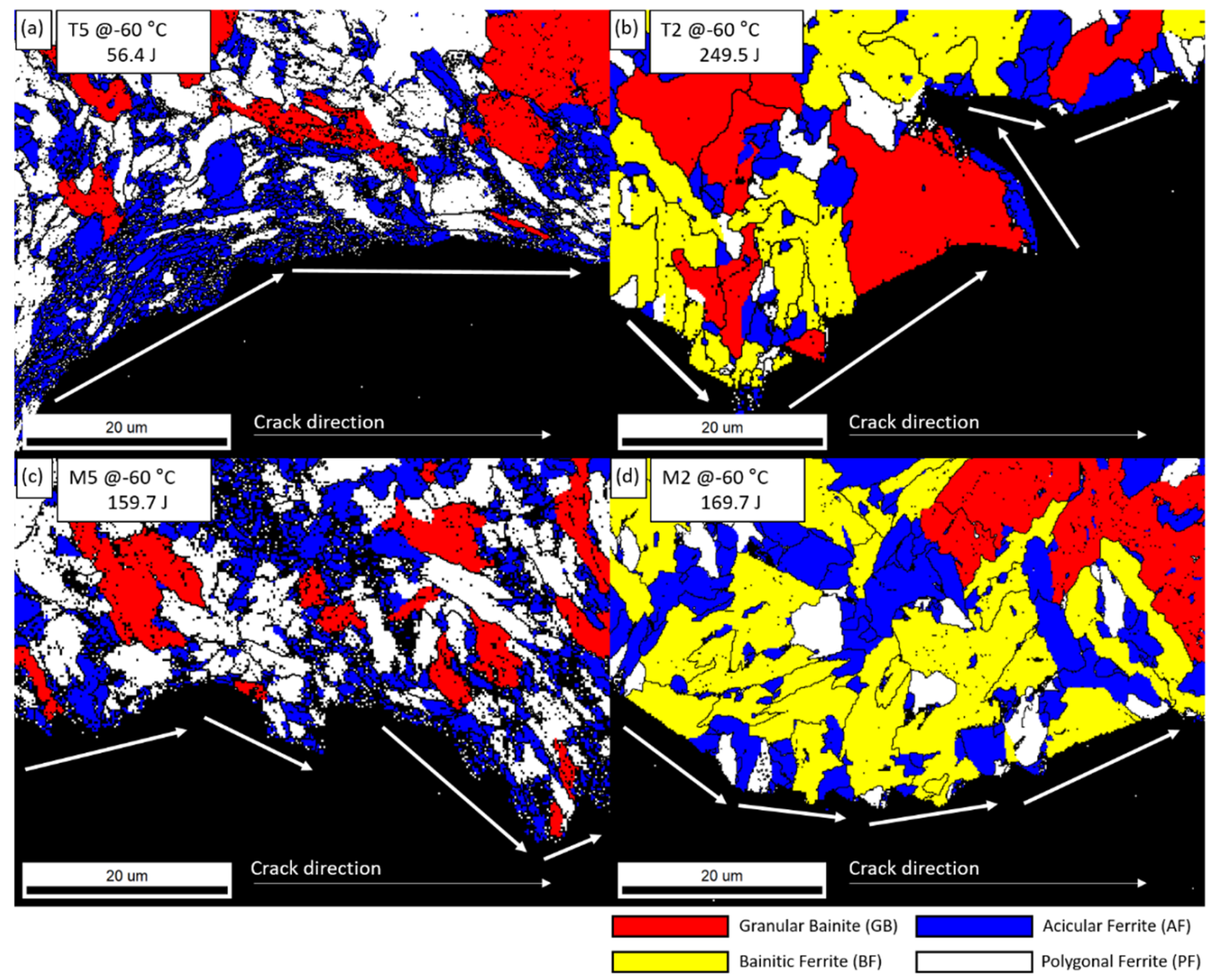

Figure 10. Phase analysis of the cross-sectional area under the fracture surface of Charpy specimens fractured at $-60{ }^{\circ} \mathrm{C}$ of the SAW heat-affected zone: (a) $5 \mathrm{~mm}$ from F.L., (b) $2 \mathrm{~mm}$ from F.L. of top; (c) $5 \mathrm{~mm}$ from F.L., (d) $2 \mathrm{~mm}$ from F.L. of middle.

Figure 11 shows the results of fracture analysis after the Charpy impact test at $-60{ }^{\circ} \mathrm{C}$ according to the location of the SAW heat-affected zone. Brittle fractures were commonly observed in the fracture surfaces in Figure 11, and large and small dimples were observed in Figure $11 \mathrm{~b}-\mathrm{d}$. At $5 \mathrm{~mm}$ from the F.L of the top (Figure 11a), the crack propagation path can be observed with a long cleavage facet, and a smooth fracture surface is shown in the crack propagation direction. Although the AF fraction was high, it can be seen that the crack resistance was low, with a packet with a similar crystal direction. A short brittle fracture was observed, and a dimple was observed crossing the fracture direction in Figure 11b,d. That is, in T2 and M2, ductile fracture surfaces, considered as fracture surfaces of finely dispersed AF, can be seen. In Figure $11 b-d$, secondary cracks can be frequently found, and it is known that they are observed when crack resistance is excellent $[46,47]$. In conclusion, it is considered that the fine dispersion of AF with HAGB is the reason for the high absorbed energy of T2 and M2. 


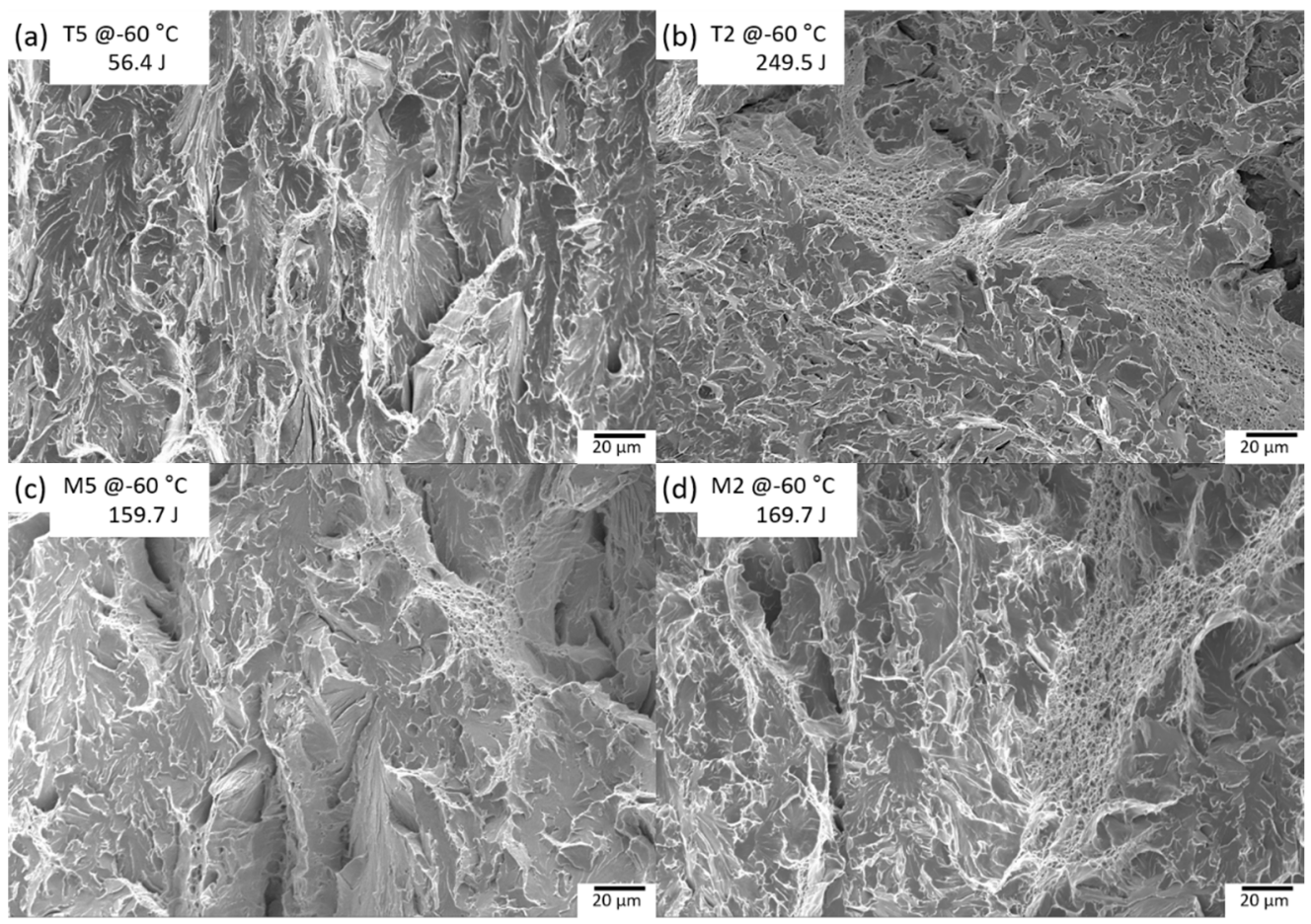

Figure 11. The fracture surface of Charpy specimens fractured at $-60^{\circ} \mathrm{C}$ of the SAW heat-affected zone; (a) $5 \mathrm{~mm}$ from F.L., (b) $2 \mathrm{~mm}$ from F.L. of top; (c) $5 \mathrm{~mm}$ from F.L., (d) $2 \mathrm{~mm}$ from F.L. of middle.

\section{Conclusions}

This study analyzed the microstructure and impact properties of an 80-mm low-carbon TMCP steel affected by the SAW process. The following conclusions were obtained:

- The present TMCP steel showed a complex bainitic microstructure with PF, AF, and GB. The microstructure fraction and grain size were changed by rolling and cooling rates. Due to the large rolling reduction rate and fast cooling rate of the surface part, the GB fraction increased toward the center, the AF fraction decreased, and the grain size increased.

- With the multi-layer SAW process, changes occur in volume fraction and grain sizes of the constituent phases such as $\mathrm{PF}, \mathrm{GB}, \mathrm{AF}$, and $\mathrm{BF}$ depending on the welding heat effect. The fractions of $\mathrm{BF}, \mathrm{AF}$, and $\mathrm{GB}$ changed as they moved away from the weld line. In the case of the central part, $\mathrm{AF}$ and $\mathrm{BF}$ of relatively small grains were observed at a faster cooling rate than the surface, and PF and GB were mainly observed in the surface.

- As a result of analyzing the effect of microstructural factors on the impact properties of TMCP steel, USE and absorbed energy depended on the microstructure fraction, and USE was improved through the absorption of impact energy of GB structure. AF structure was excellent in terms of crack resistance due to HAGB. In particular, AF dispersed in the GB and BF matrix was excellent in low-temperature toughness. However, AF packets with similar crystal orientations were vulnerable to low-temperature crack resistance.

- In the case of low-temperature impact properties, the dispersion of the AF with HAGB increases the impact absorbed energy. This is because the fine grain size and high fraction of HAGBs effectively hamper the easy propagation of cleavage cracks across the grain at low temperatures. 
Author Contributions: H.C.K. and J.B.J. conceived and designed the experiments; B.C.C. and S.J.L. performed the experiments; B.C.C., B.K. and B.J.K. analyzed the microstructure and measured the mechanical properties; J.B.J., Y.-W.C. and Y.K. discussed the data; B.C.C., Y.K. and H.C.K. wrote the paper. All authors have read and agreed to the published version of the manuscript.

Funding: This research received no external funding.

Data Availability Statement: Not applicable.

Acknowledgments: This work was supported by the Korea Institute of Industrial Technology (JA210007, Development of green-Hydrogen production system by alkaline-electrolysis/desalination and core parts).

Conflicts of Interest: The authors declare no conflict of interest.

\section{References}

1. George Krauss, S.W.T. Ferritc Microstructures in Continuously Cooled Low-and Ultralow-carbon Steels. ISIJ Int. 1995, 35, 937-945. [CrossRef]

2. Di, X.; Tong, M.; Li, C.; Zhao, C.; Wang, D. Microstructural evolution and its influence on toughness in simulated inter-critical heat affected zone of large thickness bainitic steel. Mater. Sci. Eng. A 2019, 743, 67-76. [CrossRef]

3. Lee, C.-H.; Shin, H.-S.; Park, K.-T. Evaluation of high strength TMCP steel weld for use in cold regions. J. Constr. Steel Res. 2012, 74, 134-139. [CrossRef]

4. Zhou, Y.; Jia, T.; Zhang, X.; Liu, Z.; Misra, R.D.K. Microstructure and toughness of the CGHAZ of an offshore platform steel. J. Mater. Process. Technol. 2015, 219, 314-320. [CrossRef]

5. Moon, J.; Kim, S.-J.; Lee, C. Effect of thermo-mechanical cycling on the microstructure and strength of lath martensite in the weld CGHAZ of HSLA steel. Mater. Sci. Eng. A 2011, 528, 7658-7662. [CrossRef]

6. Zhang, J.; Xin, W.; Luo, G.; Wang, R.; Meng, Q. Significant Influence of Welding Heat Input on the Microstructural Characteristics and Mechanical Properties of the Simulated CGHAZ in High Nitrogen V-Alloyed Steel. High Temp. Mater. Process. 2020, 39 , 33-44. [CrossRef]

7. Qiu, H.; Enoki, M.; Kawaguchi, Y.; Kishi, T. Evaluation of dynamic fracture toughness of welding heat-affected zone of structural steel. ISIJ Int. 2000, 40, S34-S38. [CrossRef]

8. Choi, D.; Lee, H.; Cho, S.-K.; Kim, H.C.; Hyun, S.-K.; Shin, S.Y. Microstructure and Charpy Impact Properties of FCAW and SAW Heat Affected Zones of $100 \mathrm{~mm}$ Thick Steel Plate for Offshore Platforms. Met. Mater. Int. 2020, 26, 867-881. [CrossRef]

9. Ohtani, H.; Okaguchi, S.; Fujishiro, Y.; Ohmori, Y. Morphology and properties of low-carbon bainite. Metall. Trans. A 1990, 21, 877-888. [CrossRef]

10. Hwang, B.; Lee, C.G.; Kim, S.-J. Low-Temperature Toughening Mechanism in Thermomechanically Processed High-Strength Low-Alloy Steels. Metall. Mater. Trans. A 2010, 42, 717-728. [CrossRef]

11. Hu, J.; Du, L.-X.; Wang, J.-J.; Xie, H.; Gao, C.-R.; Misra, R.D.K. High toughness in the intercritically reheated coarse-grained (ICRCG) heat-affected zone (HAZ) of low carbon microalloyed steel. Mater. Sci. Eng. A 2014, 590, 323-328. [CrossRef]

12. Kim, Y.M.; Kim, N.J. Effect of Microstructure on the yield ratio and low temperature toughness of linepipe steels. ISIJ Int. 2002, 42, 1571-1577. [CrossRef]

13. Hu, J.; Du, L.-X.; Xie, H.; Dong, F.-T.; Misra, R.D.K. Effect of weld peak temperature on the microstructure, hardness, and transformation kinetics of simulated heat affected zone of hot rolled ultra-low carbon high strength Ti-Mo ferritic steel. Mater. Des. 2014, 60, 302-309. [CrossRef]

14. Lucon, E. Mechanical tests on two batches of oxide dispersion strengthened RAFM steel (EUROFER97). Fusion Eng. Des. 2002, 61-62, 683-689. [CrossRef]

15. Takamizawa, H.; Nishiyama, Y.; Hirano, T. Bayesian Uncertainty Evaluation of Charpy Ductile-to-Brittle Transition Temperature for Reactor Pressure Vessel Steels. In Proceedings of the ASME 2020 Pressure Vessels \& Piping Conference, Las Vegas, NV, USA, 17-22 July 2020.

16. Oldfield, W. Curve fitting impact test data: A statistical procedure. ASTM Stand News 1975, 3.

17. Nikolaeva, A.V.; Nikolaev, Y.A. Mechanism of the drop in the dependence of yield stress on neutron irradiation dose for low alloy steel. Mater. Sci. Eng. A 1997, 234-236, 915-917. [CrossRef]

18. Bruchhausen, M.; Holmström, S.; Lapetite, J.M.; Ripplinger, S. On the determination of the ductile to brittle transition temperature from small punch tests on Grade 91 ferritic-martensitic steel. Int. J. Press. Vessel. Pip. 2017, 155, 27-34. [CrossRef]

19. Araki, T.; Kozasu, I.; Tankechi, H.; Shibata, K.; Enomoto, M.; Tamehiro, H. Atlas for bainitic microstructures. ISIJ Tokyo Jpn. 1992, $1,4-5$.

20. Koo, J.Y.; Luton, M.J.; Bangaru, N.V.; Petkovic, R.A.; Fairchild, D.P.; Petersen, C.W.; Asahi, H.; Hara, T.; Terada, Y.; Sugiyama, M.; et al. Metallurgical Design of Ultra-High Strength Steels for Gas Pipelines. In Proceedings of the Thirteenth International Offshore and Polar Engineering Conference (ISOPE), Honolulu, HI, USA, 25-30 May 2003.

21. Lee, M.-J.; Kang, N.-H. The Effects of Microstructure on Cold Crack in High-Strength Weld Metals. J. Korean Weld. Join. Soc. 2014, 32, 22-27. [CrossRef] 
22. ZAEFFERER, S.; ROMANO, P.; FRIEDEL, F. EBSD as a tool to identify and quantify bainite and ferrite in low-alloyed Al-TRIP steels. J. Microsc. 2008, 230, 499-508. [CrossRef]

23. Kim, D.W.; Sohn, S.S.; Kim, W.-K.; Kim, K.-S.; Lee, S. Study of Bauschinger effect of acicular ferrite and polygonal ferrite through ex-situ interrupted bending tests in API X80 linepipe steels. Sci. Rep. 2018, 8, 15598. [CrossRef]

24. Kim, D.W.; Kim, W.-K.; Bae, J.-h.; Choi, W.-D.; Sohn, S.S.; Lee, S. Effects of finish rolling temperature and yield ratio on variations in yield strength after pipe-forming of API-X65 line-pipe steels. Sci. Rep. 2020, 10, 14742. [CrossRef]

25. Han, S.Y.; Shin, S.Y.; Seo, C.-H.; Lee, H.; Bae, J.-H.; Kim, K.; Lee, S.; Kim, N.J. Effects of Mo, Cr, and V Additions on Tensile and Charpy Impact Properties of API X80 Pipeline Steels. Metall. Mater. Trans. A 2009, 40, 1851-1862. [CrossRef]

26. Kang, J.S.; Seol, J.-B.; Park, C.G. Three-dimensional characterization of bainitic microstructures in low-carbon high-strength low-alloy steel studied by electron backscatter diffraction. Mater. Charact. 2013, 79, 110-121. [CrossRef]

27. Diaz-Fuentes, M.; Iza-Mendia, A.; Gutierrez, I. Analysis of Different Acicular Ferrite Microstructures in Low-Carbon Steels by Electron Backscattered Diffraction. Study of Their Toughness Behavior. Metall. Mater. Trans. A 2003, 34A, 2505-2516. [CrossRef]

28. Lee, S.G.; Lee, D.H.; Sohn, S.S.; Kim, W.G.; Um, K.-K.; Kim, K.-S.; Lee, S. Effects of Ni and Mn addition on critical crack tip opening displacement (CTOD) of weld-simulated heat-affected zones of three high-strength low-alloy (HSLA) steels. Mater. Sci. Eng. A 2017, 697, 55-65. [CrossRef]

29. Lee, S.-I.; Lee, J.; Hwang, B. Microstructure-based prediction of yield ratio and uniform elongation in high-strength bainitic steels using multiple linear regression analysis. Mater. Sci. Eng. A 2019, 758, 56-59. [CrossRef]

30. Lee, S.; Kim, B.; Kim, W.; Um, K.-K.; Lee, S. Effects of Mo addition on crack tip opening displacement (CTOD) in heat affected zones (HAZs) of high-strength low-alloy (HSLA) steels. Sci. Rep. 2019, 9, 229. [CrossRef]

31. Eom, H.; Cho, S.K.; Cho, Y.W.; Shin, G.; Kwon, Y.; Lee, J.G.; Shin, S.Y. Effect of Carbon and Nickel on Microstructure and Low Temperature Charpy Impact Properties of HSLA Steels. Korean J. Mater. Res. 2020, 30, 184-196. [CrossRef]

32. Zuo, X.; Zhou, Z. Study of Pipeline Steels with Acicular Ferrite Microstructure and Ferrite-bainite Dual-phase Microstructure. Mater. Res. 2015, 18, 36-41. [CrossRef]

33. Jia, T.; Zhou, Y.; Jia, X.; Wang, Z. Effects of Microstructure on CVN Impact Toughness in Thermomechanically Processed High Strength Microalloyed Steel. Metall. Mater. Trans. A 2016, 48, 685-696. [CrossRef]

34. Yang, Z.; Liu, Z.; He, X.; Qiao, S.; Xie, C. Effect of microstructure on the impact toughness and temper embrittlement of SA508Gr.4N steel for advanced pressure vessel materials. Sci. Rep. 2018, 8, 207. [CrossRef] [PubMed]

35. Tarpani, J.R.; Maluf, O.; Gatti, M.C.A. Charpy impact toughness of conventional and advanced composite laminates for aircraft construction. Mater. Res. 2009, 12, 395-403. [CrossRef]

36. Kim, H.; Park, J.; Jung, J.E.; Sohn, S.S.; Lee, S. Interpretation of cryogenic-temperature Charpy fracture initiation and propagation energies by microstructural evolution occurring during dynamic compressive test of austenitic Fe-(0.4,1.0)C-18Mn steels. Mater. Sci. Eng. A 2015, 641, 340-347. [CrossRef]

37. Kim, H.; Park, J.; Kang, M.; Lee, S. Interpretation of Charpy impact energy characteristics by microstructural evolution of dynamically compressed specimens in three tempered martensitic steels. Mater. Sci. Eng. A 2016, 649, 57-67. [CrossRef]

38. Tavares, S.S.M.; Abreu, H.F.; Strohaecker, T.R.; Silva, M.B.; Macêdo, M.C.S.d. Influence of Heat Treatments on the Impact Toughness of a Ti-stabilized 12\%Cr Supermartensitic Stainless Steel. Mater. Res. 2017, 20, 469-473. [CrossRef]

39. Chaouadi, R.; Fabry, A.M. On the utilization of the instrumented Charpy impact test for characterizing the flow and fracture behavior of reactor pressure vessel steels. Eur. Struct. Integr. Soc. 2002, 30, 103-117.

40. Chaouadi, R.; Puzzolante, J.L. Loading rate effect on ductile crack resistance of steels using precracked Charpy specimens. Int. J. Press. Vessel. Pip. 2008, 85, 752-761. [CrossRef]

41. Lee, H.; Wu, X.; Kim, Y.; Kim, N. Effect of Second Phase on Mechanical Properties of Bainite-Base Steels. Adv. Mater. Res. 2007, 15, 780-785. [CrossRef]

42. Zhu, Z.; Han, J.; Li, H.; Lu, C. High temperature processed high Nb X80 steel with excellent heat-affected zone toughness. Mater. Lett. 2016, 163, 171-174. [CrossRef]

43. Rees, G.I.; Bhadeshia, H.K.D.H. Thermodynamics of acicular ferrite nucleation. Mater. Sci. Technol. 1994, 10, 353-358. [CrossRef]

44. Lee, C.H.; Bhadeshia, H.K.D.H.; Lee, H.C. Effect of plastic deformation on the formation of acicular ferrite. Mater. Sci. Eng. A 2003, 360, 249-257. [CrossRef]

45. Kim, Y.M.; Shin, S.Y.; Lee, H.; Hwang, B.; Lee, S.; Kim, N.J. Effects of Molybdenum and Vanadium Addition on Tensile and Charpy Impact Properties of API X70 Linepipe Steels. Metall. Mater. Trans. A 2007, 38, 1731-1742. [CrossRef]

46. Mao, G.; Cayron, C.; Cao, R.; Logé, R.; Chen, J. The relationship between low-temperature toughness and secondary crack in low-carbon bainitic weld metals. Mater. Charact. 2018, 145, 516-526. [CrossRef]

47. Waqas, A.; Qin, X.; Xiong, J.; Zheng, C.; Wang, H. Analysis of Ductile Fracture Obtained by Charpy Impact Test of a Steel Structure Created by Robot-Assisted GMAW-Based Additive Manufacturing. Metals 2019, 9, 1208. [CrossRef] 